(C) [2009] IEEE. Reprinted, with permission, from Xu, Wei; Zhu, Jianguo; Guo, Youguang; Li, Yongjian; Wang, Yi; Wang, Shuhong. 2009, Performance Analysis of Electrical Machine Drives for Plug-in Hybrid Vehicles', Proceedings of IEEE International Conference on Applied Superconductivity and Electromagnetic Devices, pp. 60-63.This material is posted here with permission of the IEEE. Such permission of the IEEE does not in any way imply IEEE endorsement of any of the University of Technology, Sydney's products or services. Internal or personal use of this material is permitted. However, permission to reprint/republish this material for advertising or promotional purposes or for creating new collective works for resale or redistribution must be obtained from the IEEE by writing to pubs-permissions@ieee.org. By choosing to view this document, you agree to all provisions of the copyright laws protecting it. 


\section{Performance Analysis of Electric Machine Drives for Plug-in Hybrid Electric Vehicles}

\author{
Wei Xu, Jianguo Zhu, Youguang Guo, \\ Yongjian Li,Yi Wang \\ Faculty of Electrical Engineering and Information \\ Technology, University of Technology Sydney \\ Sydney, Australia \\ wxu@eng.uts.edu.au,joe@eng.uts.edu.au
}

\author{
Shuhong Wang \\ Department of Electrical Engineering \\ Xi'an Jiaotong University \\ Xi'an, China \\ shwang@mail.xjtu.edu.cn
}

\begin{abstract}
Much attention has been paid to electric vehicles recently due to environmental concerns. The plug-in hybrid electric vehicle (PHEV) consisting of both electricity storage and gasoline tank is welcome to electric vehicle market. In the PHEV system, the electric machine drive is one of the key issues. The ideal tendency is to use the drive machine over the entire torque/speed range with high starting torque and wide constant power range. The proposed PHEV drive system in this paper has only one electric machine which functions as either a motor or generator at a time and a supercapacitor bank for fast charging and discharging during the regenerative braking and fast acceleration. The drive machine must be designed for frequent start or stop, high acceleration or deceleration, high torque or power density, and good transient performance at all speed range. This paper analyzes the new PHEV resistance power and the driving traits. The drive system is modeled and analyzed by the powertrain system analysis toolkit (PSAT) encoded in Matlab/Simulink toolbox. It compares the different driving performances between the new PHEV and one traditional vehicle in urban dynamometer driving schedule (UDDS).
\end{abstract}

Keywords-plug-in electrical vehicles (PHEV); powertrain system analysis toolkit (PSAT); drive machine; powertrain configuration; performance comparison

\section{INTRODUCTION}

Generally speaking, hybrid electric vehicle (HEV) powertrain configurations can be classified as the series, parallel, and combined parallel-series [1] [2]. The series configuration is the simplest in structure, but perhaps the lowest in efficiency due to the double energy conversion from the engine to wheels. The parallel system employs the internal compulsion engine (ICE) and the electric motor propulsion drive in parallel so that there is direct mechanical propulsion. The parallel-series system incorporates the merits of both the series and parallel systems, and hence has high efficiency and compact volume. The parallel-series structure has been applied widely in HEVs.

Fig. 1 shows the typical structure of the parallel-series system in the Toyota Prius launched in 1997 [3]. The wheels are driven by the engine directly and by the electric motor $\mathrm{M}$ while the battery is charged through the generator $G$ that is driven by the engine using a power split unit. During regenerative braking, both motor $M$ and generator $G$ can be used to charge the battery. The powertrain is designed to well suit the need of an EV that the ICE acts as the primary energy supplying source. One of the most attractive advantages of this powertrain is the electric continuously variable transmission (ECVT) functionality brought by the power split device and Generator $G$ through controlling its speed. However, the powertrain becomes complicated and requires two electrical machines which finally increase the system cost, additional copper and iron losses as well as more friction loss.

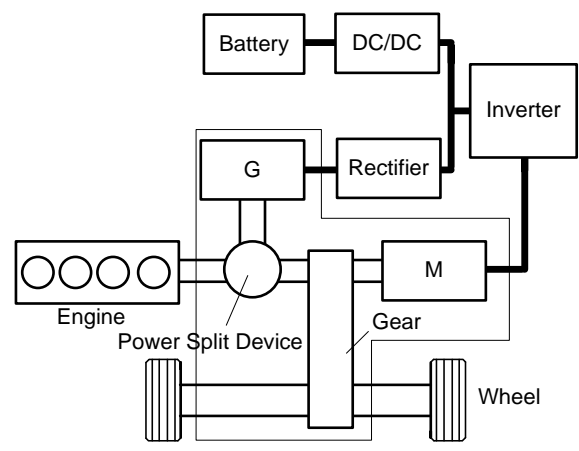

Figure 1. Toyota hybrid system configuration

If the battery of an HEV can be charged directly from the grid, it is called a plug-in hybrid electrical vehicle (PHEV). The PHEV, compared to the HEV, has a higher capacity battery that is the primary power unit while the ICE is the auxiliary one. Theoretically, ICE can only participate in acceleration or climbing process. However, the PHEV has not flooded into vehicle market due to its high cost and some unmatured technologies, such as energy management strategy, and drive system optimal control schemes [1] [2].

According to the demerits of Toyota Prius HEV system, one novel PHEV drive system has been proposed as illustrated in Fig. 2 [4]. It consists of an energy storage system involving grid-chargeable batteries in parallel with super-capacitors, a power control unit including DC link, DC/DC converters and 2-quadrant inverter/rectifier converters, an electric machine acting as motor or generator referred as MG, and an ICE mostly working in the acceleration or high torque demanding region. The most prominent trait is that only one electrical machine is required in this system, which acts as a motor in normal drive or as a generator in regenerative braking or charging of the battery and/or super-capacitor from the ICE. One proposed energy management strategy will be used in the $\mathrm{PHEV}$ to ensure the target driving performance is achieved [4]. 


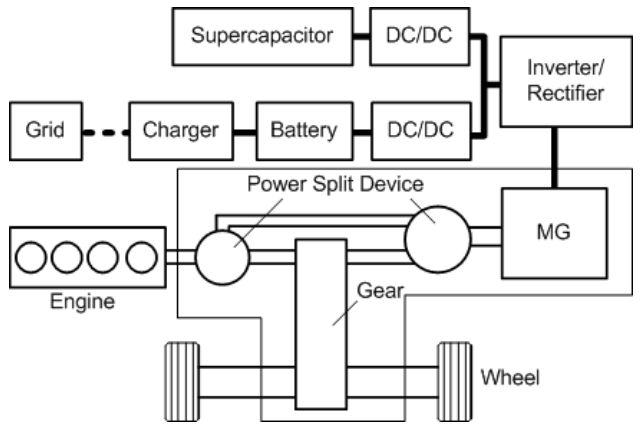

Figure 2. A novel PHEV system configuration

\section{PHEV PROPULSION AND RESISTANCE CURVES}

The vehicle performance is determined by the profile of tractive effort versus vehicle speed on the driven wheels. The ideal torque and power profiles are shown in Fig. 3. There are three regions: the constant torque region I, the constant power region II, and the reduced power region III. In relation to the road speed in Australia, the base speed is typically about 50 $\mathrm{km} / \mathrm{h}$, and the critical speed $200 \mathrm{~km} / \mathrm{h}$. During acceleration, the traction power on the driven wheels can be expressed as

$$
P_{t r}=\frac{M_{v}}{2 t_{a}}\left(V_{b}^{2}+V_{f}^{2}\right)+\frac{2}{3} M_{v} g f_{r} V_{f}+\frac{1}{5} \rho_{a} C_{D} A V_{f}^{3}
$$

where $V_{\mathrm{b}}$ is the base speed, $V_{\mathrm{f}}$ the final speed after acceleration, $M_{\mathrm{v}}$ the vehicle mass, $g$ the gravity acceleration of $9.81 \mathrm{~m} / \mathrm{s}^{2}, f_{\mathrm{r}}$ the rolling resistance coefficient, $\rho_{\mathrm{a}}$ the air mass density of $1.205 \mathrm{~kg} / \mathrm{m}^{3}, C_{\mathrm{D}}$ the aerodynamic coefficient of the vehicle, and $A$ the front area [5].

The vehicle grade ability, which completely depends on the maximum tractive effort on the driven wheel, is

$$
F_{t}=M_{v} g\left(f_{r} \cos \alpha+\sin \alpha\right)+0.5 \rho_{a} C_{D} A V^{2}
$$

where $F_{\mathrm{t}}$ is the tractive effort on the driven wheels, and $\alpha$ is the road angle. For on-road vehicles, the tractive effort usually inherently meets the grade ability requirement when the power is satisfied with the acceleration performance. Take one 1500 $\mathrm{kg}$ vehicle for example. It only needs about $48 \mathrm{~kW}$ of tractive power on the road of $5^{0}$ grade ( $8.75 \%$ tangent value) with the speed of $100 \mathrm{~km} / \mathrm{h}$, which is less than the tractive power 60 $\mathrm{kW}$ required by the acceleration performance.

The propulsion and resistance can be analyzed quantitatively on the following vehicle parameters: $M_{\mathrm{v}}=1567$ $\mathrm{kg}, t_{\mathrm{a}}=10 \mathrm{~s}, V_{\mathrm{f}}=100 \mathrm{~km} / \mathrm{h}, V_{\max }=200 \mathrm{~km} / \mathrm{h}, A=2.23 \mathrm{~m}^{2}, C_{\mathrm{D}}=0.26$, and $f_{\mathrm{r}}=0.01$.

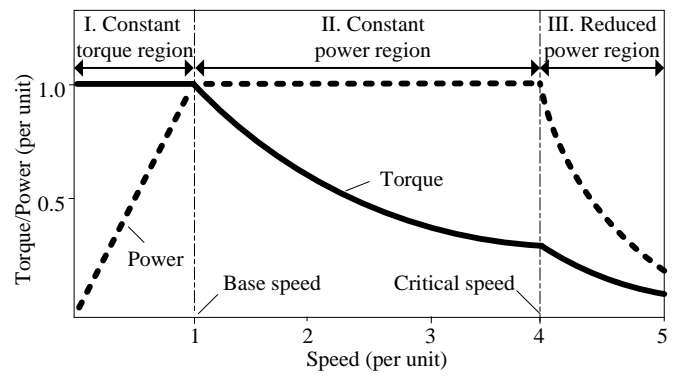

Figure 3. Ideal torque and power profiles versus speed

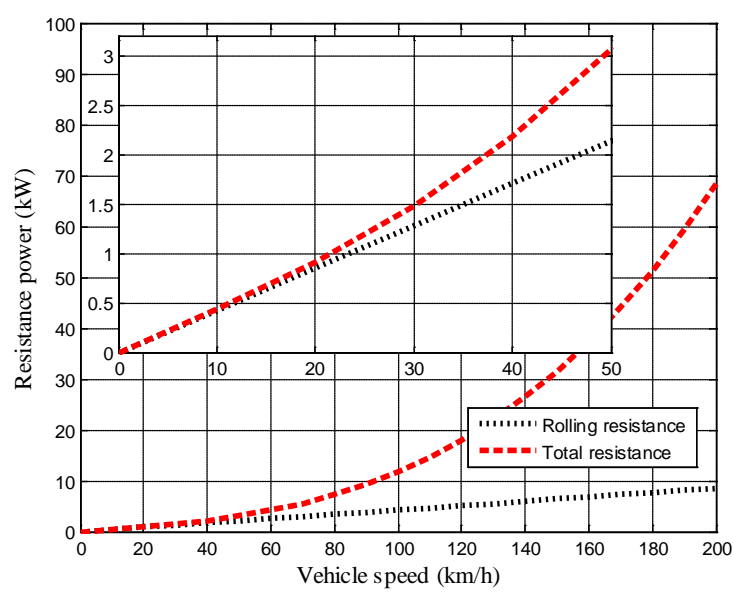

Figure 4. Resistance power versus vehicle speed

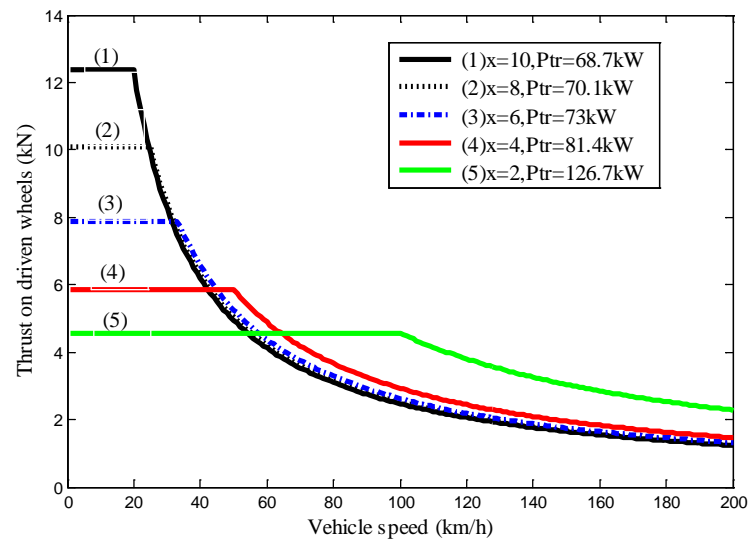

Figure 5. Thrust and power versus different speed ratio $x$

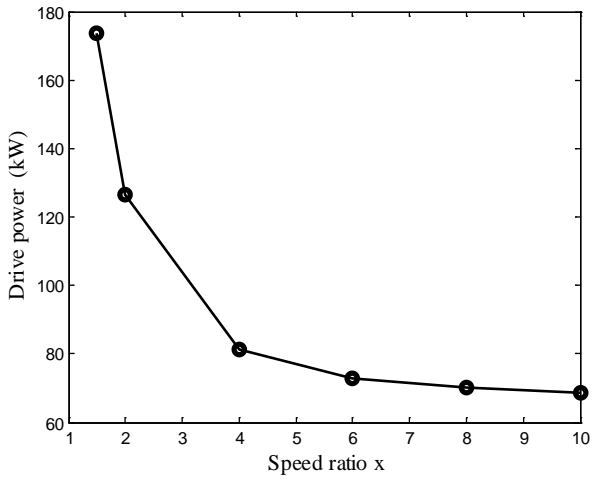

Figure 6. Drive power versus speed ratio $x$

Fig. 4 shows different resistance powers versus vehicle speed, where the rolling resistance power is in black dashed line and the aerodynamic one equals the difference between red line and black line. From the diagram, the rolling resistance power plays the most important role resulting in $70 \%$ of the total resistance at $50 \mathrm{~km} / \mathrm{h}$. The higher the speed grows the more decisive the exponentially increasing aerodynamic resistance becomes. Taking $200 \mathrm{~km} / \mathrm{h}$ for example, the rolling resistance's ratio is reduced to only $14 \%$.

Fig. 5 plots thrust and power curves versus different speed ratio $x$, which is defined as the ratio of the critical speed to the base one shown in Fig. 3. It supposes that the vehicle accelerates from zero to $100 \mathrm{~km} / \mathrm{h}$ in $10 \mathrm{~s}$ in Fig. 5, which 
indicates that the time required for the same acceleration decreases with a larger $x$, i.e. a lower base speed. However, when the speed ratio $x$ is larger than a certain value stated in Fig. 6, such as 6 , the benefit from power reduction is not great by further increase of ratio $x$. Moreover, the ratio $x$ is related closely with the drive machine type. In normal case, the ratio $x$ in the system propelled by the switched reluctance machine can reach 6 , the inductance machine 4 , and the permanent magnet machine just only 2 .

\section{PHEV MODELLING AND PERFORMANCE ANALYSIS}
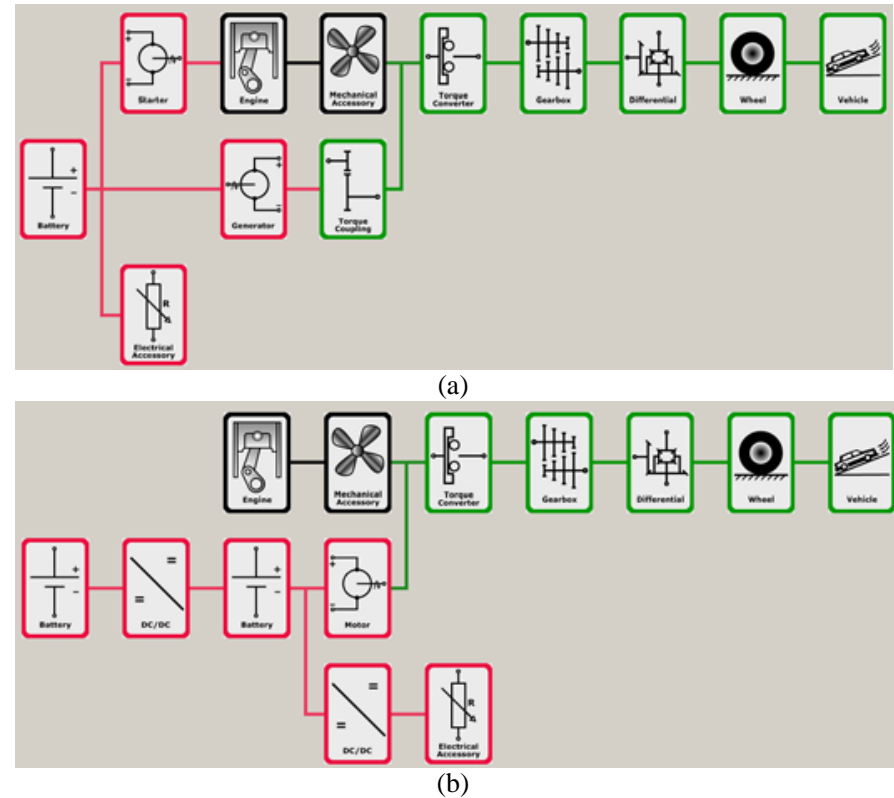

Figure 7. Simulation models built by PSAT: (a) a conventional car; (b) the proposed PHEV

The powertrain system analysis toolkit (PSAT) is adopted in our study. This tool is developed by Argonne National Laboratory, which has strong ability to evaluate both fuel consumption and vehicle performance. It operates effectively based on the Matlab/Simulink toolbox. Furthermore, it can employ a virtual driver who compares the trace speed and the actual vehicle speed, and controls the vehicle with a torque input on the base of a forward looking model. Information flows from the driver requirements through the powertrain so as to calculate plenty of outputs. PSAT allows users to create a range of powertrain configurations, such as conventional vehicles, HEVs, and fuel cell vehicles. By using test data measured at Argonne's advanced powertrain research facility, PSAT has been shown to predict the fuel economy of several hybrid vehicles within $5 \%$ accuracy on the combined cycle. It is the primary vehicle simulation package used to support the DOE FreedomCAR R\&D activities [6].

Fig. 7 includes one conventional car and the new PHEV models built by PSAT. The conventional car mainly involves one engine, mechanical accessory, torque converter, and gear box, where battery or generator works for auxiliary equipments rather than for the drive system. The PHEV system includes mainly one engine, mechanical accessory, clutch/torque converter, two energy storages involving battery and supercapacitor, etc.
Table I lists various component weights of both the conventional car and the PHEV. The conventional vehicle parameters are $A=2.69 \mathrm{~m}^{2}, C_{\mathrm{D}}=0.36, f_{\mathrm{r}}=0.01$ and wheel radius of $0.307 \mathrm{~m}$. The PHEV parameters include $A=2.23 \mathrm{~m}^{2}$, $C_{\mathrm{D}}=0.26, f_{\mathrm{r}}=0.01$, and wheel radius of $0.307 \mathrm{~m}$.

TABLE I. Weight of the Conventional Car And the Proposed PHEV

\begin{tabular}{|c|c|c|}
\hline Item & Conventional car & PHEV \\
\hline Mechanical accessory & 35 & 35 \\
\hline Clutch/Torque converter & 25 & 25 \\
\hline Energy storage 1 (supercapacitor) & - & 30 \\
\hline Motor & - & 86 \\
\hline Motor controller & - & 15 \\
\hline Gearbox & 75 & 75 \\
\hline Final drive & 20 & 20 \\
\hline Wheel axle & 100 & 100 \\
\hline Vehicle & 700 & 700 \\
\hline Exhaust after treatment & 30 & - \\
\hline Energy storage 2 (battery) & - & 150 \\
\hline Power converter-energy storage & 10 & 30 \\
\hline Power converter-electrical accessory & - & 30 \\
\hline Electrical accessory & 18 & 15 \\
\hline Engine & 262 & 120 \\
\hline Cargo & 136 & 136 \\
\hline Starter & 3 & - \\
\hline Others & 36 & - \\
\hline Total & 1450 & 1567 \\
\hline
\end{tabular}

The drive cycle is the urban dynamometer driving schedule (UDDS), while the speed-time and acceleration-speed-time curves are indicated in Fig. 8. From these two subplots, the maximal speed is $56.7 \mathrm{mile} / \mathrm{h}$ with average value of 19.58 mile/h, the maximal acceleration is $1.48 \mathrm{~m} / \mathrm{s}^{2}$ with average of $0.50 \mathrm{~m} / \mathrm{s}^{2}$, and the maximal deceleration is $-1.48 \mathrm{~m} / \mathrm{s}^{2}$ with average $-0.58 \mathrm{~m} / \mathrm{s}^{2}$. During about 1300 second duration, there are almost 17 stops.

Some performance comparison results between the traditional car and the PHEV are shown in Table II. The PHEV acceleration in short range is inferior to that of the conventional one. However, the PHEV has lower $\mathrm{CO}_{2}$ emission and better fuel economy than those of the traditional car. In the whole speed range, the drive machine in the PHEV plays the major role, while the ICE mainly takes part in the frequently quick start positions in need of high torques. The engine efficiency is almost proportional to its rotary velocity, implying that when the speed is higher, the efficiency is high. In Fig. 9, the PHEV engine can mostly operate in the $2000 \mathrm{rpm}$ range, while the traditional ones are approximately in the 1000-1500 rpm range. Therefore, the PHEV engine efficiency is $29.17 \%$, slightly higher than that of the traditional car (27.89\%) indicated in Table II. Furthermore, the PHEV braking energy can be fed back to the energy storage system involving battery and supercapacitor, hence it has higher system efficiency (90.84\%) 
than the conventional one (85\%). In 320 miles travel distance, the PHEV needs only $14.26 \mathrm{~kg}$ fuel, while the traditional one $26.75 \mathrm{~kg}$.

\section{CONCLUSION}

This paper firstly discusses the merits and demerits of the Toyota Prius typical HEV drive system launched in 1997. Then one novel PHEV drive system is studied which consists of one drive machine acting as motor or generator, and two energy storage system involving battery and supercapacitor. Based on the proposed PHEV system, the propulsion and resistance have been investigated. Moreover, it builds the simulation models of both the conventional car and the PHEV by the help of PSAT, where various performance traits are analyzed and compared.

\section{REFERENCES}

[1] Ali Emadi, Handbook of automotive power electronics and motor drives, USA: CRC press Taylor \& Francis, 2005, pp.50-100.

[2] M. Ehsani, Y. Gao, S. E. Gay, and A. Emadi, Modern electric, hybrid electric, and fuel cell vehicles, USA: CRC Press LLC, 2005,pp.100-200.

[3] H. Oba, "Characteristics and analysis of efficiency of various hybrid systems," Report of Toyota Motor Corporation, 2004, pp.935-957.

[4] S. A. Rahman, N. Zhang, and J.G. Zhu, "Modelling and simulation of an energy management system for plug-in hybrid electric vehicles," in Proc. Australasian University Power Engineering Conf., Dec. 2008, pp.1-6.

[5] M. Ehsani, "Hybrid electric vehicles: architecture and motor drives," Proceedings of the IEEE, vol. 95, no. 4, pp. 719-728, Apr. 2007.

[6] http://www.transportation.anl.gov/modeling_simulation/PSAT

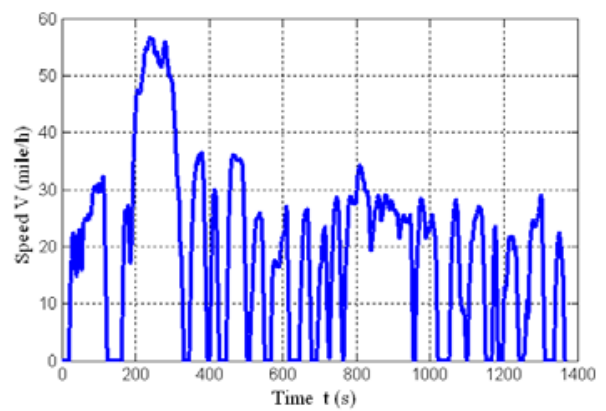

(a)

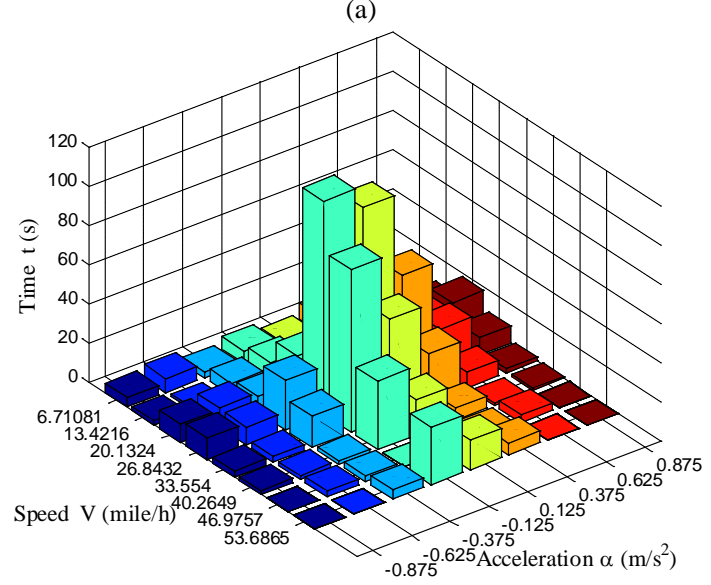

(b)

Figure 8. UDDS drive cycle: (a) speed versus time; (b) acceleration-speed versus time
TABLE II. Performance Comparison of BetweEn the ConVENTIONAL CAR AND THE PHEV IN UDDS

\begin{tabular}{|c|c|c|}
\hline Item & PHEV & Conventional car \\
\hline Acceleration in (0-60) mile/h (s) & 21.1 & 14.7 \\
\hline Distance in (0-8)s (mile) & 0.05 & 0.06 \\
\hline Time to reach 0.25 mile (s) & 22.2 & 20.5 \\
\hline Distance in (0-60)s (mile) & 0.62 & 0.71 \\
\hline \multicolumn{3}{|c|}{ Engine } \\
\hline Fuel economy (mile/gallon) & 70.91 & 33.92 \\
\hline $\mathrm{CO}_{2}$ (g/mile) & 30.43 & 266.49 \\
\hline \multicolumn{3}{|c|}{ Energy storage system } \\
\hline Battery + supercapacitor (Wh/mile) & 29.09 & -- \\
\hline Component average efficiencies \\
\hline Engine bidirectional efficiency (\%) & 29.17 & 27.89 \\
\hline System efficiency (\%) & 90.84 & 85 \\
\hline Mass of fuel needed to travel 320 miles (kg) & 14.26 & 26.75 \\
\hline
\end{tabular}

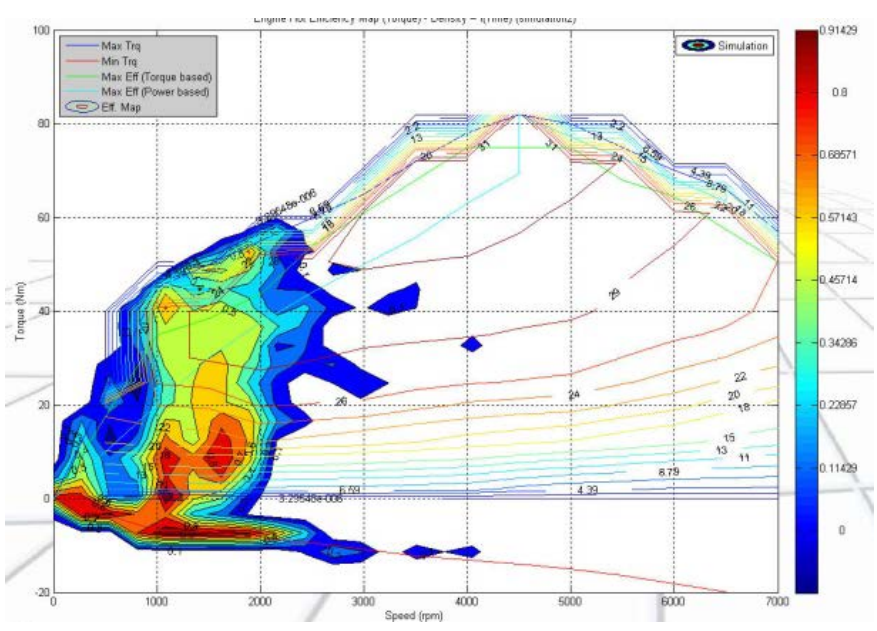

(a)

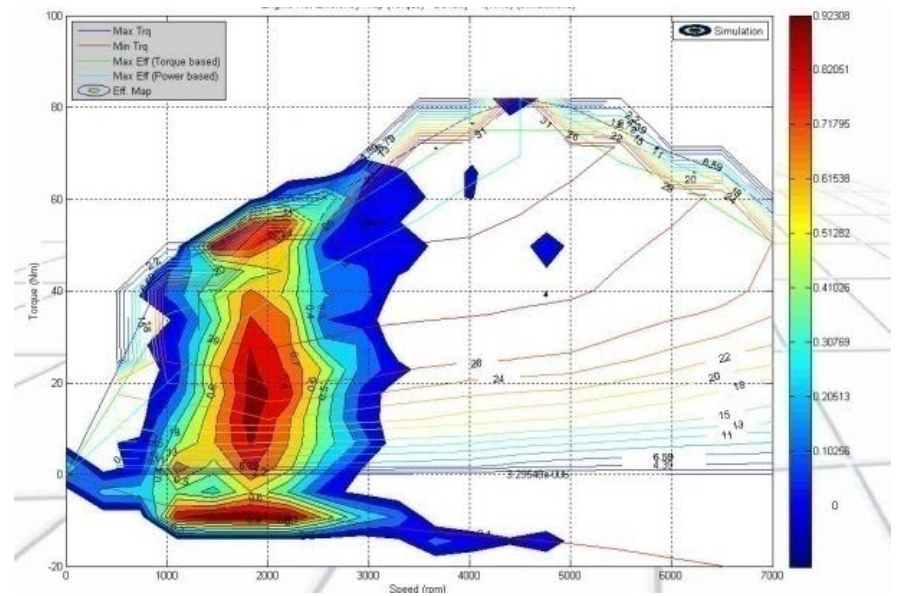

(b)

Figure 9. Engine working time-density profiles: (a) The conventional car; (b) The PHEV 